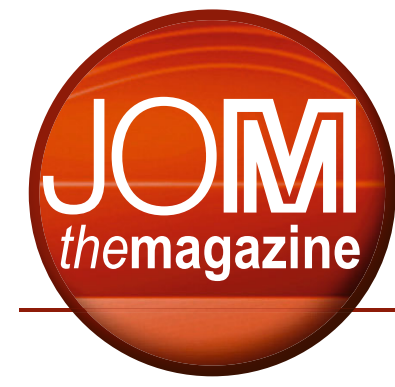

\title{
new and noteworthy at TMS
}

\section{TMS Member Contributions Highlighted at MS\&T14}

The impact of TMS members on the

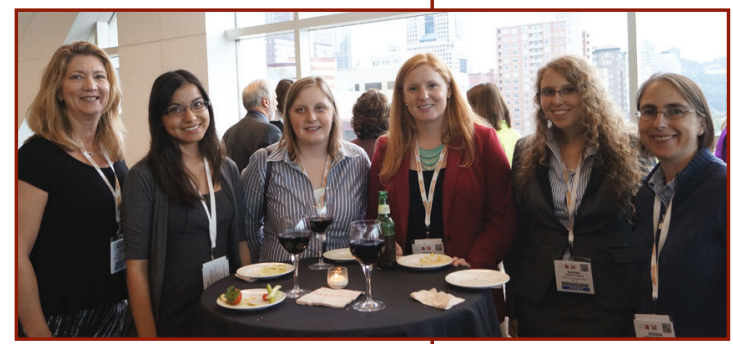

advancement of the minerals, metals, and materials field was evident throughout Materials Science \& Technology 2014 (MS\&T14), held October 12-16 in Pittsburgh,

MS\&T14 attendees enjoyed a beautiful fall day and great networking opportunities at the Women in Materials Science Reception on October 13.

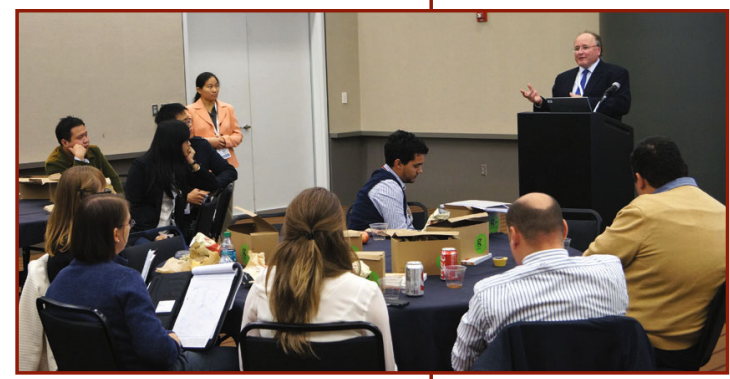

Brian Gleeson (at podium), Department Chair, Mechanical Engineering \& Materials Science, University of Pittsburgh, was the featured speaker at the TMS Young Professional Tutorial Luncheon at MS\&T14. He shared advice on choosing and pursuing a career in academia, with insights into his own journey, starting as an undergraduate student at the University of Western Ontario, to his current position.
Pennsylvania. The professional contributions of TMS members were highlighted in a number of special lectures and symposia, while TMS volunteer efforts ensured a vibrant technical

program and a successful public debut of TMS's new educational outreach project, Comictanium $^{\mathrm{TM}}$ : The Super Materials of the Superheroes.

Organized jointly by TMS, the American Ceramic Society, the Association for Iron and Steel Technology, and ASM International, and co-sponsored by NACE International, MS\&T14 attracted more than 3,200 professionals, with nearly 1,800 papers presented.

Hani Henein, TMS President, praised the work of the MS\&T14 Program

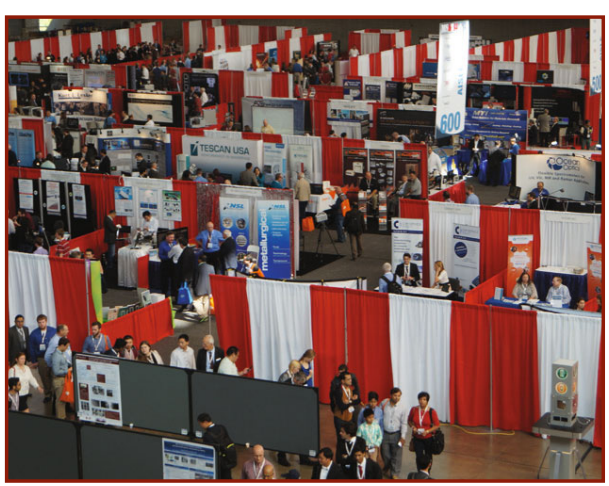

The MS\&T14 exhibition was a destination for networking and business development.
Coordinating Committee, chaired by Judy Schneider, TMS representative, for leading the development of a strong, cohesive technical program. "From the opening plenary, the meeting reflected the synergy of interests among the four organizing societies," he said. "There was a strong showing of emerging technologies, such as additive manufacturing, balanced with equally excellent symposia that explored more traditional topics. It is always impressive how MS\&T is able to blend the technical perspectives of all of the societies, while still addressing the specific meeting goals of their respective memberships."

MS\&T will next travel to Columbus, Ohio, from October 4-8, 2015. Abstracts are now being accepted for MS\&T15 on such topics as Biomaterials, Green Manufacturing and Sustainability, Materials-Environment Interactions, Processing and Product Manufacturing (including additive manufacturing), and Surface Modification. For details and to start your planning for MS\&T15, visit the meeting website at matscitech.org.

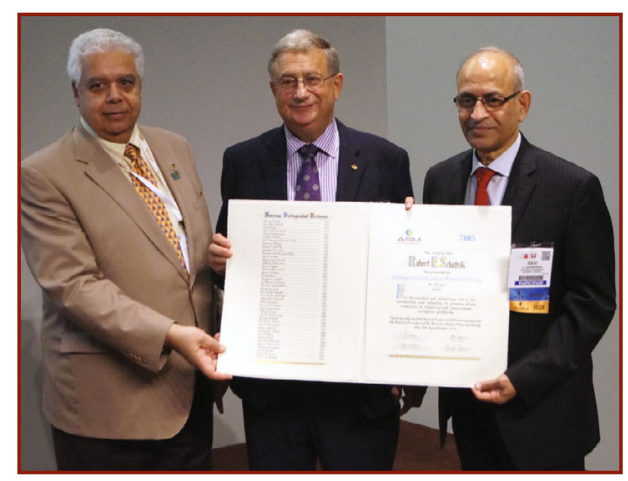

TMS President Hani Henein (left) and ASM International President Ravi Ravindran (right) present Robert E. Schafrik (center) with the 2014 Distinguished Lecturer Award. Schafrik drew on his more than 40 years of experience in the aviation industry to discuss the challenges in developing new materials for next generation applications in his lecture, "Materials for a Non-Steady State World." 


\section{MS\&T14 Opening Plenary Examines the Drivers for Advanced Manufacturing}

The technical program for MS\&T14 was rich in presentations and discussion on advanced manufacturing, with a particular emphasis on additive manufacturing developments. The all-meeting opening plenary reflected this interest, with a distinguished panel of experts presenting their perspectives on the challenges inherent in the issues that are propelling the wider adoption of these emerging technologies.

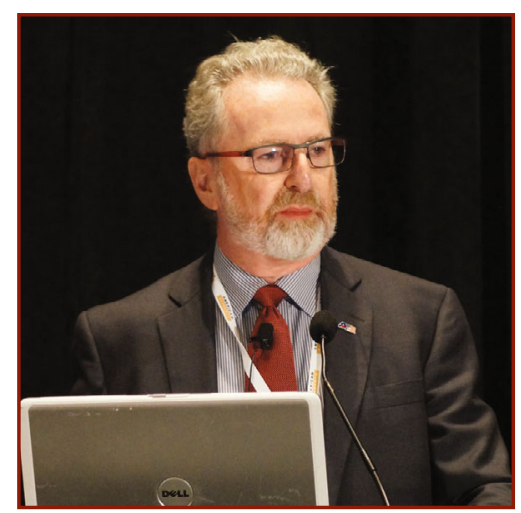

Alex King examined how advances in technology have contributed to the escalating problem of materials criticality, and the potential impact of this issue on manufacturing and innovation. To illustrate his point, King noted that a cell phone of 40 years ago used 30 elements, while the new iPhone 6 requires 75 elements.

King spoke from his experience as the current director of the Critical Materials Institute-one of the U.S. Department of Energy's Innovation Hubs-as well as his past work as the director of Ames Laboratory, to suggest potential strategies to mitigate these supply concerns. This includes recycling, although King commented, "It's easy to collect neodymium from hard disc drives, but it's hard to collect the drives from consumers."

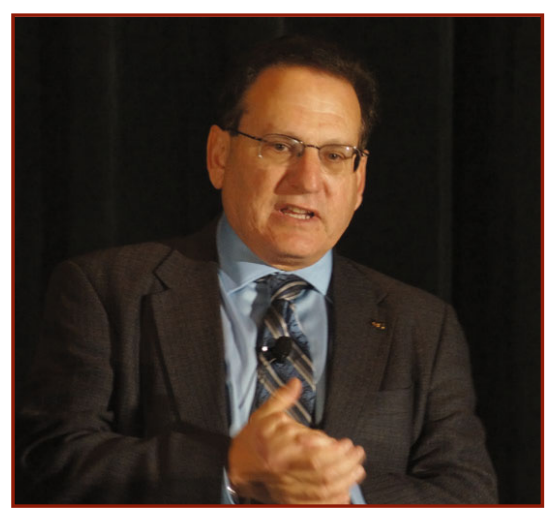

Currently the chief technical officer of the American Lightweight Materials Manufacturing Institute and a retired vice president of Global Research and Development for GM, Alan Taub focused his presentation on the challenges of improving automotive energy efficiency. The context for his discussion was the rapid global increase in operating vehicles, given the rise of a middle class in many emerging economies.

Noting that much work has been done on enhancing powertrain efficiency, Taub stressed that lightweighting through innovative materials substitution and optimization tactics was critical to achieving efficiency goals. He then discussed how materials development and commercialization needed to be accelerated through an integrated approach to design and innovation across the full supply chain.

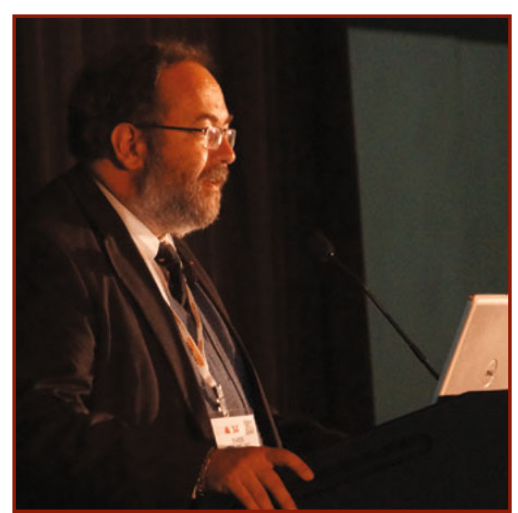

Yves Bréchet, professor, GrenobleINP and France's High Commissioner for Atomic and Alternative Energy, spoke on the challenge of minimizing the lifetime energy intensity of products. He noted that this will require complex, multifunctional materials, developed beyond the reach of current toolsets.

Traditionally, achieving new materials properties has relied on tweaking compositions or microstructures. At higher scales, geometries are modified or different types of materials are combined, as in hybrid materials. Bréchet said that between these two scales lies an alternate strategythe development of "architectured materials," that relies on an appropriate combination of materials and geometries at scales comparable to the scale of the component and tailored to meet its unique requirements. This new approach gives rise to challenges in process engineering, modeling, and manufacturing.

\section{Superalloys Scholarship Awardees Recognized}

Congratulations to the two 2015 International Symposium on Superalloys Scholarship awardees, who received formal recognition for their achievements at MS\&T14. Said Saikumar Reddy Yeratapally, Purdue University, "For a budding researcher like me, this scholarship not only serves as a recognition of my hard work and achievements, but it further motivates me to keep working hard to do great research." Luke Rettberg, University of California, Santa Barbara, likewise commented, "Being recognized for my achievements is both humbling and motivating as I continue to pursue a career in the high-temperature materials field." The scholarships are funded annually by the Organizing Committee of the International Symposium on Superalloys.

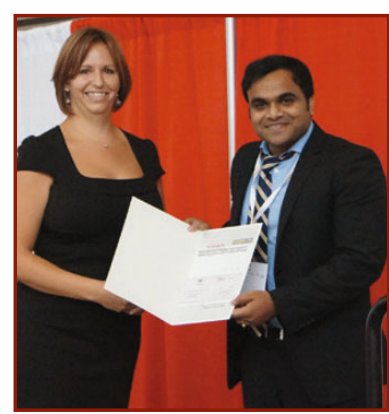

Saikumar Reddy Yeratapally (right) receives his scholarship from Marissa Riegel, Savannah River National Laboratory.

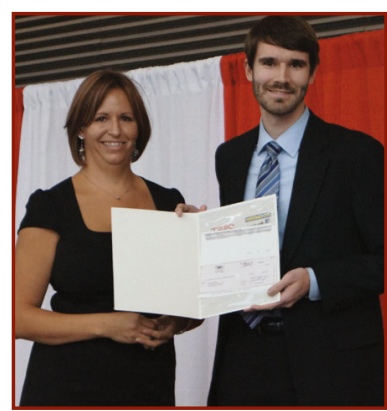

Luke Rettberg (right) receives his scholarship from Marissa Riegel, Savannah River National Laboratory. 


\section{Comic-tanium Brings Materials to the Masses}

\author{
Comic-tanium $^{\mathrm{TM}}$ : The Super \\ Materials of the Superheroes \\ officially opened to the public \\ during MS\&T14 to illustrate how \\ science and engineering actually \\ do save the world everyday through \\ the exploits of favorite comic \\ characters. \\ A lot of people got the message. \\ Starting with its opening VIP \\ reception on October 12 at the
} ToonSeum in Pittsburgh - just a few blocks from MS\&T14 activities at the David L. Lawrence Convention CenterComic-tanium attracted the attention of an array of media outlets. The focus of many of these news articles was Suveen Mathaudhu, TMS volunteer curator for the project, as he enthusiastically spread the word about the importance of attracting more young people to the science and engineering disciplines, using comics as a fun and accessible teaching tool. "Comic

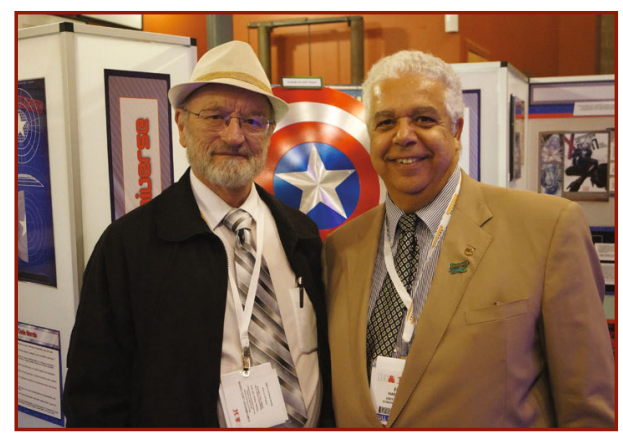

Hani Henein (right), 2014 TMS President, and Stanley Howard, incoming TMS Vice President, were among the TMS volunteer leaders who celebrated the opening of Comic-tanium during the VIP reception.

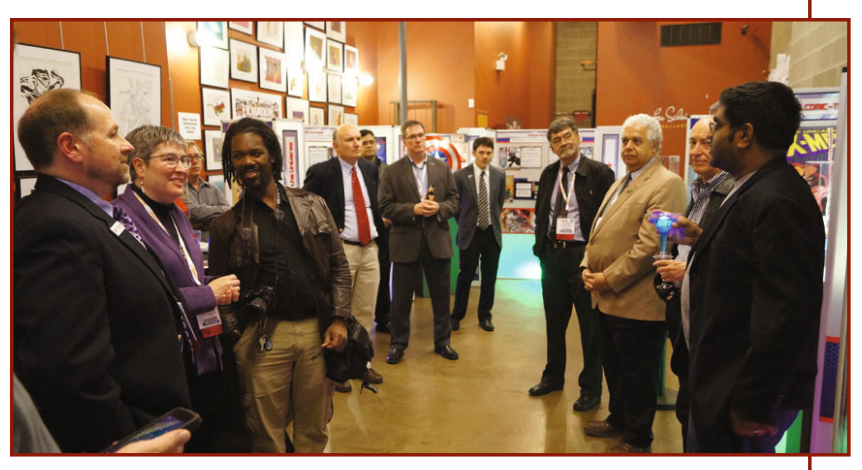

books have always been a microcosm of what we are, and I am really happy that we can use them as an outreach tool to reach the broader community and convey these important concepts," he said in an interview with the Pittsburgh Tribune Review. Comic-tanium also made a notable national appearance when it was featured in the opening clip on NBC Sunday Night Football on December 28.

"It was a delight seeing Comic-tanium make its public debut in Pittsburgh," said Hani Henein, TMS President. "I was so pleased that TMS was able to coordinate this with MS\&T so that many from the materials community could see for themselves what a special and important project this is."

An ad hoc committee appointed by the TMS board is planning for the next phase of Comic-tanium. Details will be revealed in upcoming issues of JOM. In the meantime, visit the Comic-tanium website at tms.org/comictanium to access the media coverage that project has generated to raise awareness of the minerals, metals, and materials professions.

\section{TMS Launches Honorary Membership Program}

Beginning in 2016, TMS will extend honorary membership status to selected candidates nominated by members of the minerals, metals, and materials community. The new TMS Honorary Membership Award is a prestigious distinction reserved for nontraditional candidates - people who do not fit the usual TMS member profile, but through excellence in both personal reputation and career achievements, have made a positive impact on minerals, metals, materials, or related fields and industries. This program also gives TMS the ability to recognize people in leadership roles who may not have the technical background of a typical TMS member, but who have still contributed to the advancement of minerals, metals, or materials.

Honorary members will receive a full, professional membership in TMS for life. Nominees cannot be current or recent members of the society. For additional information and to access the nomination form, visit the TMS Professional Honors and Awards website at awards.tms.org. Nominations for 2016 are being accepted until April 1, 2015.
Suveen Mathaudhu (far right), TMS volunteer curator for Comic-tanium, gave a private tour to MS\&T leadership at a VIP reception to publicly kick off the exhibit. This event brought Comic-tanium full circle for Mathaudhu, an assistant professor at the University of CaliforniaRiverside. He initially developed the concept for Comic-tanium while visiting the ToonSeum during MS\&T when the meeting was last held in Pittsburgh in 2012. 


\section{Energy Materials 2014 Launches New Collaboration}

Set in the ancient city of Xi' an, China, Energy Materials 2014 made a little history of its own, kicking off a series of events organized collaboratively by TMS and the Chinese Society for Metals (CSM).

The two organizations built upon their already strong relationship to develop Energy Materials 2014 as the inaugural meeting for a series of conferences
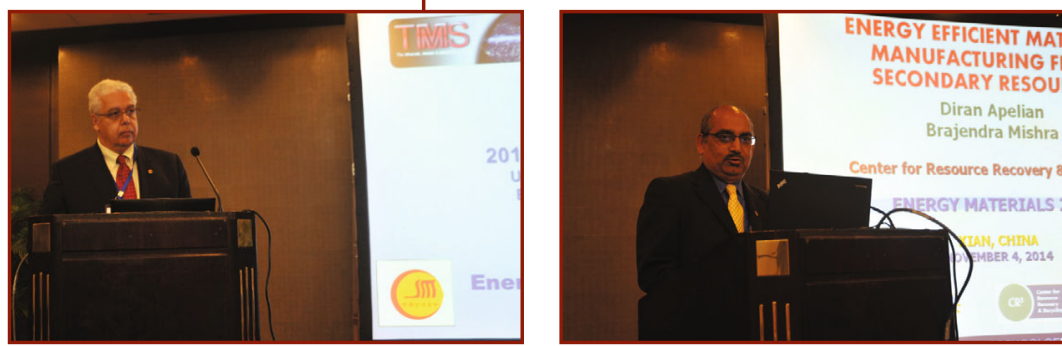

Hani Henein (photo left), TMS President, and Brajendra Mishra (photo right), 2006 TMS President, were both opening plenary speakers and paper presenters at Energy Materials 2014. Henein kicked off the opening plenary with an overview of TMS activities on energy topics, while his presentation later that day shared his work on the development of microalloyed steels for oil and gas pipelines. Mishra's opening plenary talk focused on the need and strategies for recycling rare earth elements. His paper presentation examined the challenges of microbiologically influenced corrosion on steel pipeline networks.

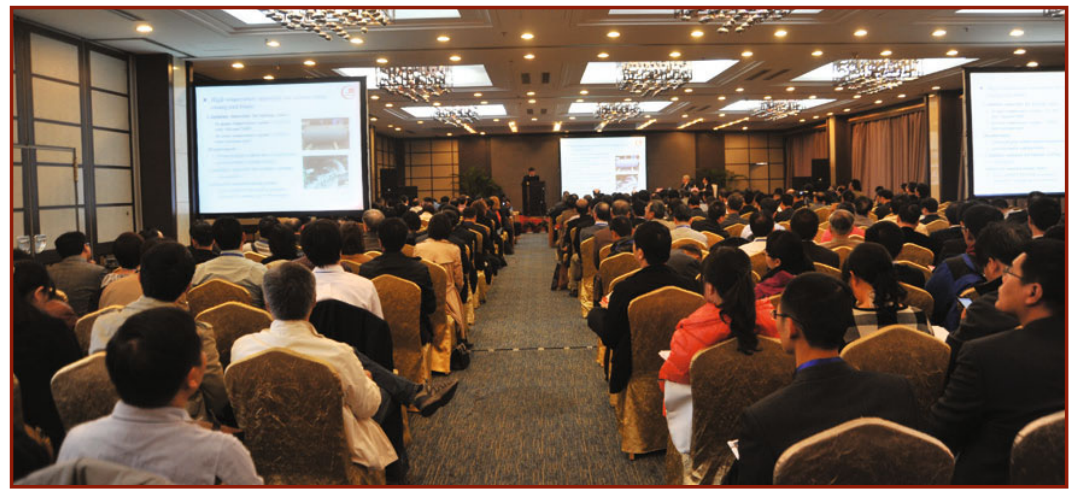

More than 300 science and engineering professionals attended Energy Materials 2014.

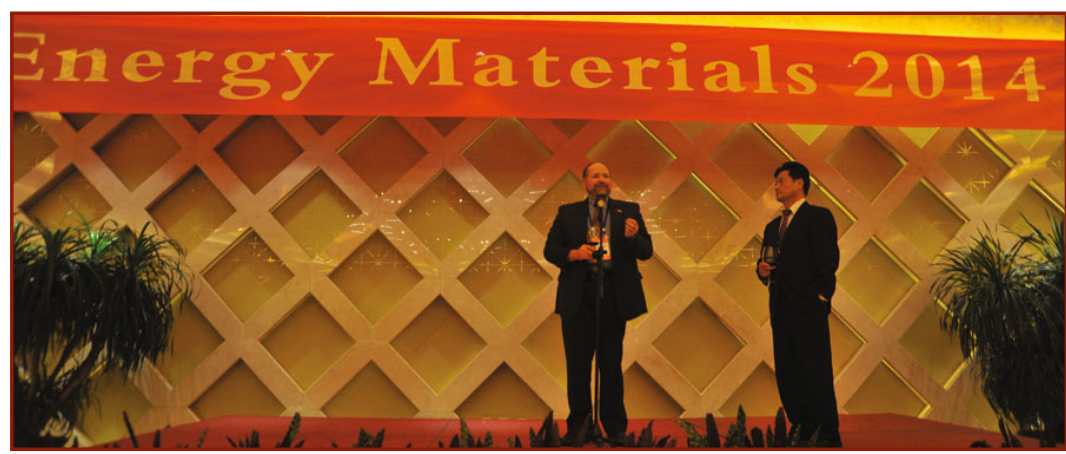

James J. Robinson (left), TMS Executive Director, and Zhao Pei, CSM Secretary General, toasted their respective organizations' warm collaboration, as well as a productive inaugural conference, at the Energy Materials 2014 banquet. planned to be held every two years. With a focus on traditional energy industries and technologies, such as pipelines and boilers, the meeting, held November 4-6, drew more than 300 science and engineering professionals from throughout the world and offered more than 120 presentations. The learning and sharing spilled outside of the packed meeting rooms as well, facilitated by a number of formal and informal networking functions.

Xingbo Liu, professor and Associate Chair for Research, West Virginia University, and the lead conference organizer representing TMS, pointed to the "excellent collaboration between TMS and CSM at all levels and in all aspects" as the major contributor to the meeting's success. "There was a good collection of technical talks, but it was also a very valuable meeting for building friendships and professional connections worldwide," he said.

Planning is underway for TMS-CSM Energy Materials 2016 - this time set in the United States - with details to be announced later this year. In the meantime, CSM and TMS have issued a call for abstracts for their next new collaboration, the 1st International Conference on Computational Designs and Simulations in Materials, scheduled for August 17-20 in Shenyang, China. The deadline for abstracts is May 15. Visit www.cdsm2015 .com for additional information and to submit an abstract online.

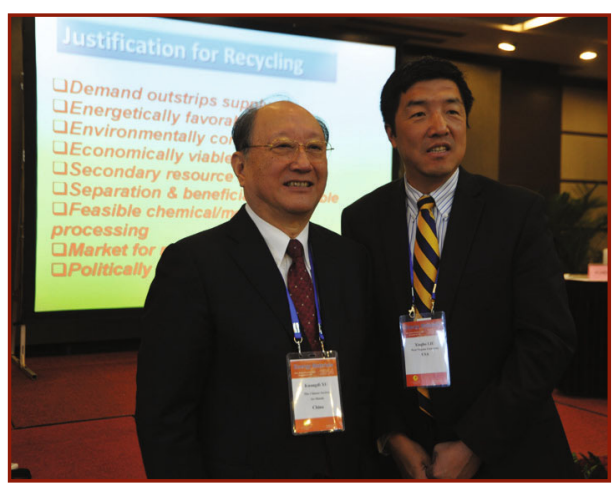

Xingbo Liu (right), lead conference organizer representing TMS, congratulates TMS-CSM Energy Materials 2014 Honorary Chairman Kuangdi Xu on a successful meeting. Xu was President of CSM at the time and is Honorary President of the Chinese Academy of Engineering. 


\section{COM 2014 Explores "Prosperity through Process Improvements"}

More than 600 members of the extractive metallurgy community gathered in Vancouver, British Columbia, for the 53rd Annual Conference of Metallurgists (COM 2014), organized by the Metallurgy and Materials Society (MetSoc) of the Canadian Institute of Mining, Metallurgy, and Petroleum (CIM). Co-sponsored by TMS, and with a number of TMS members in attendance, COM 2014 was built on the theme "Prosperity through Process Advancements," with all 13 of its symposia focused on current issues and developments in processing.

In addition to presenting technical advancements, COM 2014, held September 28-October 1, examined the state of the profession through a panel discussion with the leadership from six international professional organizations on the role of extractive metallurgical societies. Hani Henein, TMS President and a MetSoc past president, gave a presentation on TMS's initiatives, saying, "TMS links upstream and downstream-extraction through application and recycling by facilitating collaboration of members within the academic and industrial communities." Henein then provided an overview of the TMS Extraction \& Processing Division and presented the extractive metallurgy highlights for the TMS 2015 Annual Meeting \& Exhibition, March 15-19, in Orlando, Florida. He concluded his presentation with a brief synopsis of TMS's strategic goals, highlighting TMS's initiatives related to advancing diversity and inclusion, accelerating industrial engagement, and expanding international activities as being most impactful on the extractive community.

COM 2015 will take place August 23-26 in Toronto, Ontario. For additional information, visit web.cim.org/com2015.

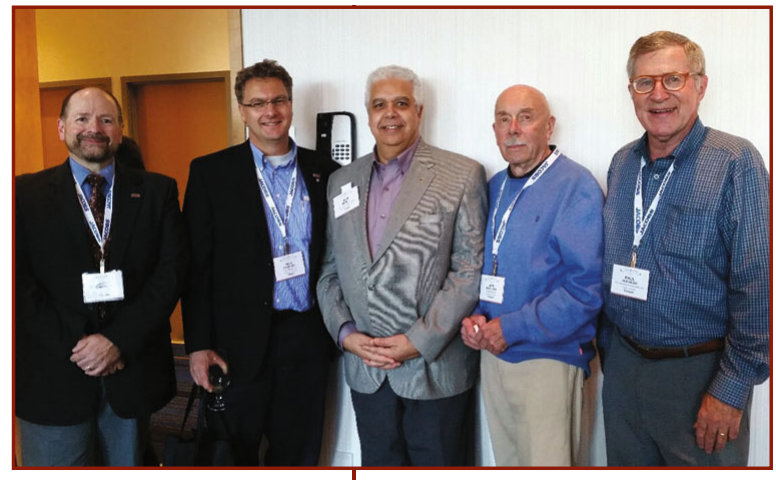

TMS members and leadership connected with their colleagues throughout the global extractive community at the 2014 Conference of Metallurgists. A few photographed at the meeting's opening reception are (from left): James J. Robinson, TMS Executive Director; Robert L. Stephens, Teck Metals; Hani Henein, 2014 TMS President and past MetSoc president; Jan Matousek, consultant; and Paul B. Queneau, The Bear Group.

\section{COM 2014 Plenary Debates the Balance Between Business Practices}

\section{Boyd Davis, MetSoc President and COM 2014 Conference Chair}

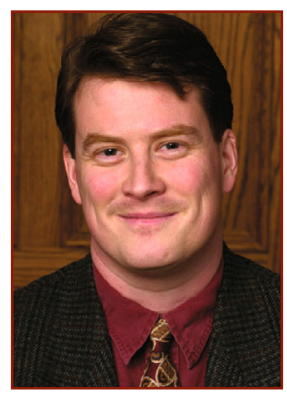

In keeping with COM 2014's theme, "Prosperity through Process Improvements," the meeting's traditional plenary format was replaced with discussion on the balance between incremental changes in operations compared with new process implementation. It is clear that a company should not focus on only one of these areas, but in the last few decades, the pendulum has swung

significantly from one side to the other.

Consolidation, increased commodity price volatility, new technologies, the rise of Asia in both production and consumption of metals, heightened environmental concerns, shareholder demands for better capital efficiency, and many other factors have made this an interesting time in the metals business. Companies are debating whether to put more capital into near-term operational improvements yielding operational excellence or into technological developments leading to a step-change in performance. The COM 2014 plenary featured four highly experienced metallurgists debating the relative balance between the two business practices, and the circumstances that tilt the scales in one direction over the other.
Nils Voermann, Hatch, and Jean-Francois Turgeon, Tronox, advocated the technological step-change approach. Michael Agnew and Phillip Mackey, both consulting after long careers in the industry, supported the operational excellence side of the equation. I moderated the session as conference chair.

The presenters were tasked with stimulating debate among conference attendees, and part of the plenary was given over to the audience to ask questions and provide thoughtful feedback. Some of the conclusions for the operational excellence side focused on the fact that there is a very wide range of quality of operations and the right people implementing the right practices can have a significant impact on profitability with marginal capital expenditures. The team supporting technological stepchange argued that only with major new technologies can a significant advantage be gained in the industry. Overall, the outcome was gauged by the audience to be virtually a tie. The major theme running through the debate was that to be truly successful, a company needs to have each of these characteristics, but the method of their implementation was critical to success.

The intent of the plenary was to extend discussion beyond the session and into the corridors and other activities at the conference. It was nice to see that throughout the conference, many people were overheard in corridors and at events debating points from the plenary.

The plenary was recorded and can be viewed at web.cim.org/COM2014/conference/Plenary.cfm. 


\section{TMS Welcomes New Members}

\section{Please join us in congratulating the following new TMS members, approved by the TMS Board of Directors at its October 2014 meeting:}

Ahmed, Omar; American University of Iraq, Iraq

Altenhof, William; University of Windsor, Canada

Andersen, Dag Herman; Hydro Aluminum, Norway

Basson, Frederic; Novelis PAE, France

Beach, Geoffrey; USA

Bernier, Joel; Lawrence Livermore National Laboratory, USA

Bi, Zhongnan; Central Iron \& Steel Research Institute, China

Brossia, Christopher; Argus Technologies, USA

Castaneda, Homero; The University of Akron, USA

Chen, Qing; Thermo-Calc Software AB, Sweden

Cheng, Bill; Vesuvius Advanced Ceramics, China

Church, J. Geoffrey; Managed Refractory Products, Canada

Clements, Todd; CMK, USA

Craig, Jarod; II-VI Infrared, Germany

Darimont, Carolyne; ArcelorMittal Dofasco, Canada

Dary, Francois; H.C. Starck, USA

De Masi, Barbara; Industrie De Nora, Italy

DelaCruz, Wilfredo; Alcoa, USA

Domanski, David; ABB Inc., Canada

Fahey, Stephen; EPIR Technologies Inc., USA

Funke, Kelly; USA

Gartner, Kevin; USA

Guosheng, Chen; Baosteel America Inc., China

Harwig, Dennis; The American Welding Society, USA

Heidloff, Andrew; Praxair Surface Technologies Inc., USA
Henry, Jason; Dow Corning Corp., USA

Hirai, Shinji; China

Jones, Nicholas; Naval Surface Warfare Center, USA

Julliand, Martine; Constellium Technical Center, China

Kang, Daehoon; Novelis Inc., USA

Kazantseva, Nataliya; Institute of Metal Physics, China

Keller, Robert; National Institute of Standards and Technology, Germany

Kim, Dongkyu; Korea Atomic Energy Research Institute, Russia

Kosters, Jared; Nexight Group LLC, USA

Kuetemeyer, Marius; USA

Kukla, Maija; National Science Foundation, USA

Kumar, Amit; ExxonMobil Upstream Research Co. USA

Lastrapes, Tim; USA

Li, Lin; Shanghai University, China

Li, Mingyang; Beijing Beiye Functional Materials Corp., China

Lifton, Anna; ALPHA Metals Inc., USA

Lilleodden, Erica; HehelmholtzZentrum Geesthacht, Germany

Lord, Thomas; Seco/Warwick, USA

Lowry, Matthew; USA

Maharaj, Moahni; China

Mesquita, Rafael; CBMM, USA

Miletto Granozio, Fabio; CNR-SPIN, USA

Minakshi, Manickam; Murdoch University, Australia

Mingjian, Hua; University of Pittsburgh, USA

Mirshams, Reza; University of North Texas, USA
Mukhtarov, Shamil; Institute for Metals Superplasticity Problems, Russia

Namduri, Haritha; General Electric Co., USA

Natishan, Paul; Naval Research Laboratory, USA

Nauman, John; Consarc Corp., USA

Norris, Jacob; Special Metals Corp., USA

Obara, Richard; Emerson Climate Technologies, USA

Pei, Xinhua; China

Pitz, Marcel; General Electric Co., USA

Rajan, Vaidyanath; The Lincoln Electric Co., USA

Ray, Atish; McMaster University, Canada

Reiterer, Markus; Medtronic Inc., USA

Richardson, Chris; Laboratory for Physical Sciences, USA

Rozenburg, Keith; Schott North America Inc., USA

Safarzadeh, Sadegh; South Dakota School of Mines \& Technology, USA

Safizadeh, Fariba; Laval University, Canada

Schmidt, Jeff; Solenis, USA

Sellmyer, David; University of Nebraska, USA

Shamberger, Patrick; Texas A\&M University, USA

Sharma, Satyajeet; USA

Simien, Daneesh; University of Alabama at Birmingham, USA

Siw, Sean; USA

Smith, David; GIVA, USA

Stratis-Cullum, Dimitra; United States Army Research Laboratory, USA

Sun, Amy; Sandia National Laboratories, USA

Takahashi, Ribeka; Brigham Young University, USA
Tasooji, Amaneh; Arizona State University, USA

Tassa, Oriana; Centro Svilluppo Materials SpA, Italy

Taylor, Richard; USA

Thompson, Carl; Massachusetts Institute of Technology, USA

Tong, Jintao; Central Iron \& Steel Research Institute, China

Varanasi, Chakrapani; Army Research Office, USA

Villalobos, Guillermo; USA

Vogli, Evelina; USA

Wang, Gang; Tsinghua University, China

Wang, Hang; Jiangxi University of Science \& Technology, China

Watson, Thomas; Pratt \& Whitney, USA

Whittingham, Stanley; NorthEast Center for Chemical Energy Storage, USA

Whittington, Abby; Virginia Polytechnic Institute and State University, USA

Wie, Xie; Baosteel Special Metals Co., Ltd., China

Withey, Elizabeth; USA

Woods, Joseph; Philips Lighting Co., USA

Worledge, Daniel; IBM Thomas J. Watson Research Center, USA

Xia, Wentang; Chongqing University of Science and Technology, China

Xiong, Hui; Boise State University, USA

Yao, Zhihao; China

Yin, Jianguo; Chongqing University of Science and Technology, China

Zeagler, Andrew; USA

Zhang, Xian; Naval Surface Warfare Center, USA

Zixing, Wang; Baosteel Special Metals Co. ,Ltd., China 